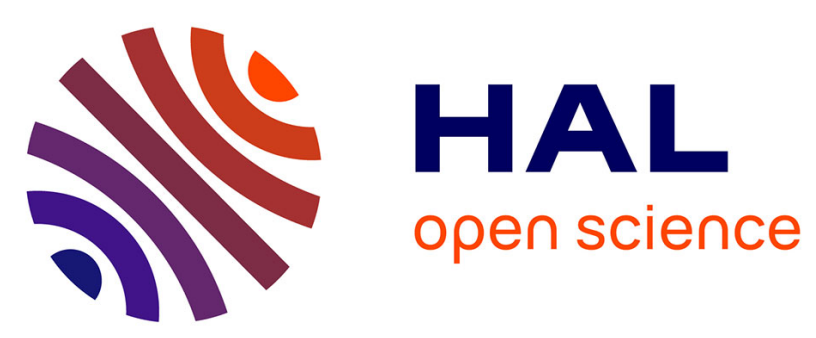

\title{
Parametric study of the mechanical properties of nanocrystalline TiN/CrN multilayer coatings with a special focus on the effect of coating thickness and substrate roughness
}

T.D. Atmani, M. Gaceb, H. Aknouche, C. Nouveau, M.S. Bouamrene

\section{To cite this version:}

T.D. Atmani, M. Gaceb, H. Aknouche, C. Nouveau, M.S. Bouamrene. Parametric study of the mechanical properties of nanocrystalline $\mathrm{TiN} / \mathrm{CrN}$ multilayer coatings with a special focus on the effect of coating thickness and substrate roughness. Surfaces and Interfaces, 2021, 23, pp.101001. 10.1016/j.surfin.2021.101001 . hal-03222732

\section{HAL Id: hal-03222732 \\ https://hal.science/hal-03222732}

Submitted on 10 May 2021

HAL is a multi-disciplinary open access archive for the deposit and dissemination of scientific research documents, whether they are published or not. The documents may come from teaching and research institutions in France or abroad, or from public or private research centers.
L'archive ouverte pluridisciplinaire HAL, est destinée au dépôt et à la diffusion de documents scientifiques de niveau recherche, publiés ou non, émanant des établissements d'enseignement et de recherche français ou étrangers, des laboratoires publics ou privés. 


\title{
Parametric study of the mechanical properties of nanocrystalline TiN/CrN multilayer coatings with a special focus on the effect of coating thickness and substrate roughness
}

\author{
T.D. Atmani ${ }^{\mathrm{a}, *}$, M. Gaceb ${ }^{\mathrm{a}}$, H. Aknouche ${ }^{\mathrm{b}}$, C. Nouveau ${ }^{\mathrm{c}}$, M.S. Bouamrene ${ }^{\mathrm{b}}$ \\ ${ }^{\text {a }}$ Laboratoire de Fiabilité des Equipements Pétroliers et Matériaux Université M'hamed Bougara Boumerdes, Avenue de l'Independence 35000, Algeria \\ ${ }^{\mathrm{b}}$ UR-MPE Université M'hamed Bougara, Boumerdes, Avenue de l'Independence 35000, Algeria \\ ${ }^{\mathrm{c}}$ Arts et Metiers Institute of Technology, LABOMAP, HESAM Université, F-71250 Cluny, France
}

A R T I C L E I N F O

\section{Keywords:}

$\mathrm{TiN} / \mathrm{CrN}$

structure

roughness

thickness

interfaces

adhesion

\begin{abstract}
A B S T R A C T
In a plot to improve the performance of steel mechanical parts subject to aggressive friction solicitations, three batches of deposits of TiN and CrN layers on steel substrates with two different roughnesses have been obtained using reactive DC magnetron sputtering. The present study was conducted to determine the effect of varying TiN/CrN multilayer coatings thickness (varying modulated period $\Lambda$ and interlayer thickness), on their mechanical and tribological properties. The morphological and the structural properties were analyzed using scanning electron microscopy (SEM) and X-ray diffraction (XRD). The nanoindentation measurements displayed improvement in hardness ( $>40 \mathrm{GPa}$ ) and Young's modulus ( $>600 \mathrm{GPa})$ for the coating with $\Lambda \cong 12 \mathrm{~nm}(\mathrm{TiN}$ $\Lambda / 2 \cong 7.5 \mathrm{~nm}+\operatorname{CrN} \Lambda / 2 \cong 4.5 \mathrm{~nm}$ ) thickness and the higher number (300) of interfaces, deposited on the rougher substrate. Its low coating damage under the scratch test, associated with its estimated adhesion work $\left(W_{a d}\right)$, indicated a good cohesive/adhesive strength and improved structural and mechanical properties.
\end{abstract}

\section{Introduction}

In order to improve the wear resistance performance of mechanical parts subjected to aggressive friction stresses, investigations have been carried out for many years in the field of hard coatings since the improvement of tribological properties cannot be achieved without increasing its hardness, strain tolerance and toughness. Several authors have associated the wear resistance to crack formation events which were found to have a strong influence on mechanical properties [1-5]. Moreover, Bull [6] suggested scratch testing which provides a closer approximation in abrasive wear behavior. Increasing coating hardness and adhesion are considered as the key factors controlling wear resistance of the surface. The most universal characteristic of the mechanical properties of the coatings is their hardness, which largely determines their resistance to abrasive wear. Indeed, Koehler [7] was the first to propose stratified structure that hinders crack propagation at interfaces. Multilayer thin films generally exhibit better mechanical properties and thermal stability compared to their monolayer counterparts [8-10]. A $\mathrm{TiN} / \mathrm{ZrN}$ system with hardness above $44 \mathrm{GPa}$ were obtained for a bilayer period of $\Lambda \approx 10 \mathrm{~nm}$ with a layer thickness ratio of $1.5 / 1$. Moreover coatings with asymmetric layer thicknesses provided a better hardness behavior compared to those with equal layer thicknesses [11]. The TiN/CrN multilayer coating, in particular, is a technologically important system. Investigations into these multilayer coatings continue to be carried out to highlight their mechanical and tribological behavior [12-16]. Indeed, the performances of TiN/CrN multilayer coatings were found to be associated with the modulated period $(\Lambda)$, crystallographic orientation, grain size, residual stresses and the coating surface roughness. Nevertheless, the varying TiN/CrN thickness effect, associated with substrate roughness has rarely been reported.

The aim of our study is to present the structure, and mechanical properties of TiN/CrN multilayered coatings deposited on XC48 steel substrates. The substrate surface roughness and the modulation wavelength variation effect on the mechanical properties, namely the hardness and the resistance to plastic deformation $\mathrm{H}^{3} / \mathrm{E}^{* 2}$, were examined. Additionally the damage mechanisms during scratch tests and an estimation of the adhesion work $\mathrm{W}_{\mathrm{ad}}$ of multilayered coatings were also considered. The TiN/CrN multilayer coatings were deposited using reactive DC magnetron sputtering process, a widely used technique for multilayer deposition. It is a flexible and effective technique that offers

\footnotetext{
* Corresponding author.

E-mail address: t.atmani@univ-boumerdes.dz (T.D. Atmani).
} 
many advantages such as nanolayered thickness controlling and structure tailoring.

\section{Experimental details}

\subsection{Film deposition technique}

Successive $\mathrm{TiN}$ and $\mathrm{CrN}$ layers with different modulation periods were deposited on Silicon (100) samples $\left(10 \times 10 \times 0.38 \mathrm{~mm}^{3}\right.$ and $10 \times$ $\left.20 \times 0.38 \mathrm{~mm}^{3}\right)$ and XC48 steel substrates $\left(10 \times 10 \times 4 \mathrm{~mm}^{3}\right.$ and $25 \times 25$ $\times 4 \mathrm{~mm}^{3}$ ). The TiN/CrN multilayer depositions were conducted in an industrial DC magnetron sputtering system (KENOSISTEC K540V) having a semi-cylindrical shape (550 $\mathrm{mm}$ diameter, $600 \mathrm{~mm}$ height and 370 liters), equipped with four targets. Prior to the coating deposition, the steel samples were divided in two groups. The two groups of samples were polished to mirror finish with $(120$ - 800) and $(120$ - 1200) grit SiC paper corresponding to a surface roughness Ra value of approximately $0.09 \mu \mathrm{m}$ and $0.04 \mu \mathrm{m}$, respectively measured with an optical profilometer (VEECO-Wyko NT-1100). They were then cleaned ultrasonically in acetone for 10 minutes, rinsed in alcohol at $95^{\circ}$ before being mounted in the vacuum chamber. The samples were fixed on one of the eight substrate-holders mounted on the rotating carrousel. The target to substrate distance was $120 \mathrm{~mm}$. The chamber was pumped down to 2.2 $\times 10^{-5}$ mbar for the three deposits. The high purity Ti (99.95\%) and $\mathrm{Cr}$ (99.99\%) targets were pre-sputtered for about 15 minutes while the substrates were isolated from the plasma by a shutter, to allow their cleaning with $99.99 \%$ purity argon gas flow rate at $50 \mathrm{sccm}$. To promote film densification the deposition temperature was $300^{\circ} \mathrm{C}$. The samples were in-situ etched under an argon flux for 15 minutes in order to remove the residual oxides and promote adhesion, using a negative substrate bias voltage of - $500 \mathrm{~V}$. Furthermore, to promote coating adhesion and facilitate the TiN nucleation, the deposition sequence started, for all coatings, with a very thin metallic Ti interlayer growth up to $\approx 10 \mathrm{~nm}$ thickness as a bond layer onto the substrates. A $40 \mathrm{sccm}$ flow of nitrogen was then introduced into the chamber as a reactive gas and the total $\mathrm{Ar}+\mathrm{N}_{2}$ gas pressure was maintained at $3.9 \times 10^{-3}$ mbar. The individual layer thicknesses in each TiN/CrN multilayer were controlled by adjusting the ( $\mathrm{Ti}$ and $\mathrm{Cr}$ ) target power supplies and by adapting the carousel rotation speed and scan numbers with a programmable logic controller (PLC). Preliminary deposition tests with individual TiN and $\mathrm{CrN}$ coatings were performed before $\mathrm{Ti} / \mathrm{TiN} / \mathrm{CrN}$ coating depositions, in order to estimate the coating growth trend with the target power (target power and rotary speed of the carrousel). Three architectures of the coatings were produced: (a) a multilayer with a constant sequence, approximately $20 \mathrm{~nm}$ (100 TiN layers of $10 \mathrm{~nm}$ thickness each and 100 CrN interlayers of $10 \mathrm{~nm}$ thickness each); (b) a multilayer with varying sequence ranging from $\cong 40$ to $10 \mathrm{~nm}$ (100 TiN layers: $20 \times(20 \mathrm{~nm}+$ $15 \mathrm{~nm}+10 \mathrm{~nm}+7.5 \mathrm{~nm}+5 \mathrm{~nm})$ and $100 \mathrm{CrN}$ interlayers: $20 \times(20 \mathrm{~nm}+$ $15 \mathrm{~nm}+10 \mathrm{~nm}+7.5 \mathrm{~nm}+5 \mathrm{~nm}$ )); and finally (c) a multilayer with a constant sequence approximately $12 \mathrm{~nm}(150 \mathrm{TiN}$ layers of $\approx 7.5 \mathrm{~nm}$ thickness each and $150 \mathrm{CrN}$ interlayers of $\approx 4.5 \mathrm{~nm}$ thickness each). Details of deposition parameters are summarized in Table 1 . In the following, it has been decided to call the 3 different types of multilayers on different substrates roughnesses as TiN/CrN-1 (A and B), TiN/CrN-2 (C and D) and TiN/CrN-3 (E and F). The configurations of TiN/CrN multilayers are shown in Fig. 1.

\subsection{Characterizations}

The microstructure and mechanical properties of the coatings were determined using conventional methods. Surface morphology and crosssectional SEM observations were examined using scanning electron microscopy (SEM, Jeol JSM $5900 \mathrm{LV}, 15 \mathrm{kV}$ ) combined with energy dispersive spectrometry (EDS) and wavelength dispersive spectrometry (WDS) (Oxford INCA $\mathrm{x}$ - act) in order to determine and quantify the chemical composition at operating voltages of 15 and $5 \mathrm{kV}$.

The crystallographic structure and crystallite size of the coatings were characterized by X-Ray diffraction (XRD) generated by a Phillips $X$ 'pert thin film diffractometer ( $45 \mathrm{kV}$ and $40 \mathrm{~mA}$ ) in the Bragg-Brentano configuration ( $\mathrm{Cu} \mathrm{K \alpha}$ as the radiation source $\left(\lambda_{\mathrm{cu}}=0.15406 \mathrm{~nm}\right)$ ). The scanning has been performed at an angle ranging from 20.025 to 99.975 degrees, for which the angle size and the score time at each step were set to $0.05^{\circ}$ and $1 \mathrm{~s}$, respectively. The incidence angle was $5^{\circ}$. The crystallite size and strain of the thin films was deduced from XRD through the Williamson-Hall plot method, using the High Score Plus software.

The residual stresses in the coatings were determined using the Stoney equation [17]. The radii of curvature of the silicon substrate before and after deposition were measured using an optical profilometer (VEECO-Wyko NT 1100).The roughnesses of the uncoated and coated substrate were also measured using an optical profilometer.

In addition to the surface morphology and crystal structure of the coatings, their mechanical properties were studied. The hardness $(H)$, and the effective Young's modulus $\left(E^{*}\right)$ were assessed by the nanoindentation technique. The measurements were performed in a continuous stiffness measurement (CSM) mode. Using a Berkovich indenter, the applied load on the sample surfaces was increased to a maximum of $10 \mathrm{mN}$, at a preset rate of $20 \mathrm{mN} / \mathrm{min}$ and then decreased at the same rate to 0 at $10 \mathrm{~Hz}$. The indentation depth was kept below $1 / 10^{\text {th }}$ of the film thickness (Buckle's rule 1959), so that to eliminate the substrate's effect $[4,18-20]$. The roughness did not have much influence on the nanoindentation measurement. Indeed, it was less than $5.5 \%$ as compared to the indentation depth on each multilayer. Measurements were repeated 8 times for each sample. The hardness was calculated using the Oliver and Pharr method [21].

Likewise, to compare adhesion properties of the TiN/CrN multilayer, the adhesion behavior was investigated using an automatic scratch instrument «Scrach Tester Millenium $200 »$ monitored by acoustic emission (sensitivity set to $2 A E$ ). The coating damages were determined by load diagrams and confirmed by optical microscopy. The samples were scratch tested at an initial normal load of $1 N$, which was gradually

Table 1

Coating periods, thicknesses and roughnesses

\begin{tabular}{|c|c|c|c|c|c|c|c|c|c|c|}
\hline $\begin{array}{l}\text { Multilayer } M \\
=\text { TiN } / \mathrm{CrN}\end{array}$ & $\begin{array}{l}\text { Sputtering } \\
\text { Power (W) }\end{array}$ & $\begin{array}{l}\text { Target Bias } \\
\text { voltage }(-V)\end{array}$ & $\begin{array}{l}\text { Growth } \\
\text { rate (nm/ } \\
\text { min) }\end{array}$ & $\begin{array}{l}\text { Carousel } \\
\text { rotation speed } \\
(\mathrm{rpm})\end{array}$ & $\begin{array}{l}\text { Period } \Lambda \\
(\mathrm{nm})\end{array}$ & $\begin{array}{l}\text { Period } \\
\text { number } \\
\left(\mathrm{n}_{\mathrm{i}}\right)\end{array}$ & $\begin{array}{l}\text { Layer } \\
\text { thickness } \Lambda \\
/ 2(\mathrm{~nm})\end{array}$ & $\begin{array}{l}\text { Total } \\
\text { thickness } \\
( \pm 0,05 \mu \mathrm{m})\end{array}$ & $\begin{array}{l}\mathrm{Ra}(\mathrm{nm}) \text { on } \\
\mathrm{Si}(100 \times \\
\left.100 \mu \mathrm{m}^{2}\right)\end{array}$ & $\begin{array}{l}\text { Residua } \\
\text { stresses } \\
\text { (MPa) }\end{array}$ \\
\hline $\begin{array}{l}\text { TiN/CrN-1 } \\
\quad\left(\mathrm{Ti}[M] \mathrm{n}_{1}\right)\end{array}$ & $\begin{array}{l}\text { Ti } 2000 \\
\text { TiN } 2000 \\
\text { CrN750 }\end{array}$ & $\begin{array}{l}388 \\
388 \\
346\end{array}$ & $\begin{array}{l}- \\
5.05 \\
5.10\end{array}$ & 0.5 & $\approx 20$ & 100 & $\begin{array}{l}10.3 \\
\approx 10 \\
\approx 10\end{array}$ & 2.03 & 5.5 & +66.88 \\
\hline $\begin{array}{l}\text { TiN/CrN-2 } \\
\quad\left(\mathrm{Ti}[M] \mathrm{n}_{2}\right)\end{array}$ & $\begin{array}{l}\text { Ti } 2000 \\
\text { TiN } 2000 \\
\text { CrN } 750\end{array}$ & $\begin{array}{l}388 \\
388 \\
346\end{array}$ & $\begin{array}{l}- \\
5.05 \\
5.10\end{array}$ & $\begin{array}{l}\text { Ranging } \\
0.25-0.4- \\
0.5-0.8-1\end{array}$ & $\begin{array}{l}\text { Ranging } \\
\approx 40-10\end{array}$ & 100 & $\begin{array}{l}\approx 10 \\
\text { Ranging } \\
\approx 20-5\end{array}$ & 2.30 & 7 & -155.55 \\
\hline $\begin{array}{l}\mathrm{TiN} / \mathrm{CrN}-3 \\
\quad\left(\mathrm{Ti}[M] \mathrm{n}_{3}\right)\end{array}$ & $\begin{array}{l}\text { Ti } 2500 \\
\text { TiN } 2500 \\
\text { CrN } 700\end{array}$ & $\begin{array}{l}391 \\
391 \\
325\end{array}$ & $\begin{array}{l}- \\
7.5 \\
4.5\end{array}$ & 1 & $\approx 12$ & 150 & $\begin{array}{l}\approx 10 \\
\approx 7.5 \\
\approx 4.5\end{array}$ & 1.78 & 3 & -162.78 \\
\hline
\end{tabular}




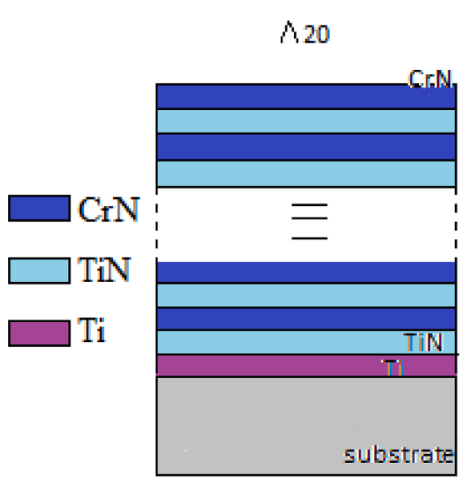

(a)

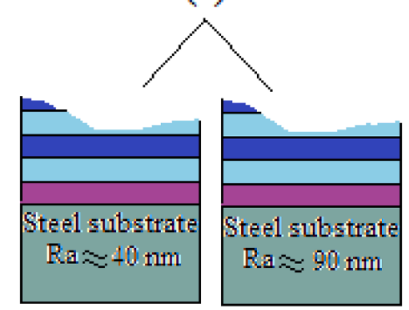

(A)
(B)

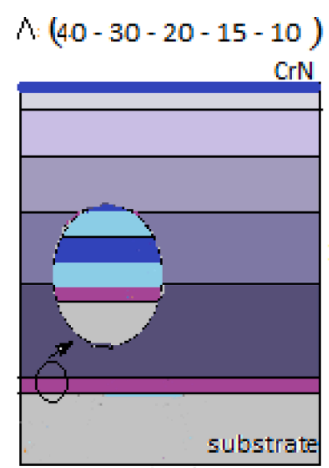

(b)

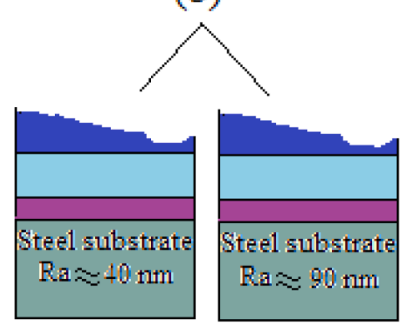

(C)

(D)

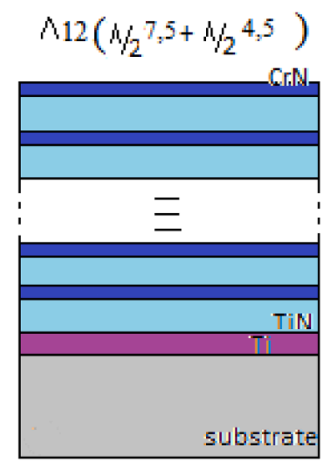

(c)

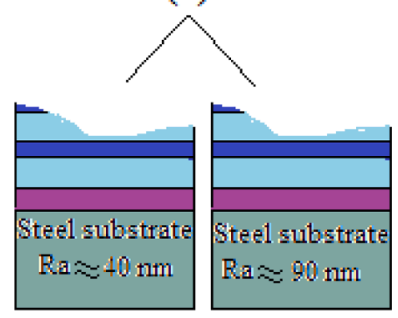

(E)

(F)

Fig. 1. Schematic illustrations of coatings, (a) TiN/CrN-1, (b) TiN/CrN-2 and (c) TiN/CrN-3 on silicon substrate; A, B, C, D, E and F on steel substrate.

increased to a final load of $21 \mathrm{~N}$ at a loading ratio of $10 \mathrm{~N} / \mathrm{mm}$ for a scratch length of $8 \mathrm{~mm}$. All the scratch adhesion testing (repeated 5 times for each sample) was performed with a Rockwell C diamond tip having a radius of $200 \mu \mathrm{m}$ and a cone angle of $120^{\circ}$.

\section{Results and discussion}

\subsection{Morphology and structure}

The $\mathrm{R}_{\mathrm{a}}$ values are calculated over a $100 \times 100 \mu \mathrm{m}^{2}$ surface area using an optical profilometer (Table 1 and Fig. 2). One can notice a notable difference in sample roughness after coating with $\mathrm{TiN} / \mathrm{CrN}$, for both the rough and smooth coated substrates.

As shown in SEM cross-sectional images (Fig. 3), it is observed that the three TiN/CrN multilayers deposited on Si substrate exhibited a dense columnar structure with a fine grain size and a smooth morphology. The TiN/CrN-1, however, exhibited a slightly less dense structure which may be due to variation in layer thickness [22], and hence, the tensile stresses generated in the coating. It is noted that the three coatings have no significant difference between their structures. The interfaces with the substrates are clear, with no particular defect except for multilayer -3 , which presented less adhesion. The coating thickness was in the range of 1.73 to $2.35 \mu \mathrm{m}$.

The EDS-WDS microanalyses revealed the presence of $\mathrm{N}, \mathrm{Ti}$ and $\mathrm{Cr}$ chemical compounds with small amounts of oxygen $(3.1-5.8 a t \%)$. The identical distribution, in all the coatings, suggested that they were closely related, bearing in mind that the EDS analysis yields only the mean chemical composition of the coatings. The calculated $\mathrm{N} /(\mathrm{Ti}+\mathrm{Cr})$ ratio $(0.64,0.66$ and 0.68$)$ for multilayers $-1,-2$ and -3 , respectively, revealed that the coatings were sub-stoichiometric. However, Nordin and Larsson [23] found that it is possible to stabilize the cubic- $\mathrm{NaCl}$ phase of the $\mathrm{CrN}$ even at small deviations from the stoichiometric composition if the lamellae are kept thin. Likewise, it was established that the stoichiometry of TiNx, with $\mathrm{x}$ values comprised between 0.4 and1.2, are thermodynamically stable $[24,25]$. Similarly, the residual stresses also improved from $+66.88,-155.55$ to $-162.78 \mathrm{MPa}$ with the stoichiometric ratios. The calculated $\mathrm{Ti} /(\mathrm{Ti}+\mathrm{Cr})$ ratio increased from $\cong$ 0.51 to 0.58 as the Ti target power increased from 2000to $2500 \mathrm{~W}$, which is in accordance with work by Nordin and Larsson [23]. These differences in composition will lead to differences in the mechanical properties. Given the difficulty in X-ray analysis of accurately separating the nitrogen K-line from the titanium L-level, the calculations below (Table 2) are given approximately

\subsection{X-Ray diffraction analysis}

The crystalline microstructure of TiN/CrN multilayers deposited on $\mathrm{Si}(100)$ and steel substrate, suggested $\mathrm{NaCl}$ face centered cubic (fcc) type structure of titanium and chromium nitride, the results are in agreement with the JCPDS cards $n^{\circ} 00-38-1420$ and $n^{\circ} 00-003-1157$ respectively. A predominance of texture of crystallite with the [100] axis was observed, with variable intensities, in all the samples [23, 26, 27]. Indeed, the TiN as the starting layer of the films, has favored the phase (200) orientation growth of the films, in accordance with the literature $[9,23]$. Additionally, Nordin and Larsson [23] noted the influence of thicknesses of the individual layers constituting the multilayers, on their texture. For sufficiently fine strata, the texture (200) is systematically observed. This is also confirmed by Yang et al. [9]. As suggested by Pelleg et al [29], the preferred orientation of the coatings is controlled by their competition to minimize the overall energy. Besides, it should be noted that growth with the [100] axis (a plane in fcc (200) lattice) occurs at a low bias potential [28]. The TiN/CrN-2 (C and D) structures with a low period on surface $(\Lambda \approx 10 \mathrm{~nm})$, as well as for TiN/CrN-3 (E and F) structures $(\Lambda \approx 12 \mathrm{~nm})$, were composed of one principal reflection centered at approximately $43.078^{\circ}, 43.171^{\circ}$, $43.037^{\circ}$ and $42.91^{\circ}$, respectively, located between the $\operatorname{TiN}_{(200)}$ and $\mathrm{CrN}_{(200)}$ theoretical reflection angles $\left(42.8^{\circ}\right.$ and $\left.43.8^{\circ}\right)$, and flanked by first order satellite arrowed in Fig. 4(a) and (b). These peaks are slightly shifted to a higher diffraction angle side. This can be related to the development of compressive stresses. The single-phase present, a face-centered cubic (fcc) structure, and the strong (200) texture suggested a good epitaxial growth of $\mathrm{CrN}$ on TiN. This phenomenon was reported by several authors [9, 15, 18, 30, 31] who suggested the superlattice phase formation and related this to the decreased modulation period. A less preferred texture growth was otherwise observed for the TiN/CrN-1 coatings. The cumulative diffraction peaks observed in 

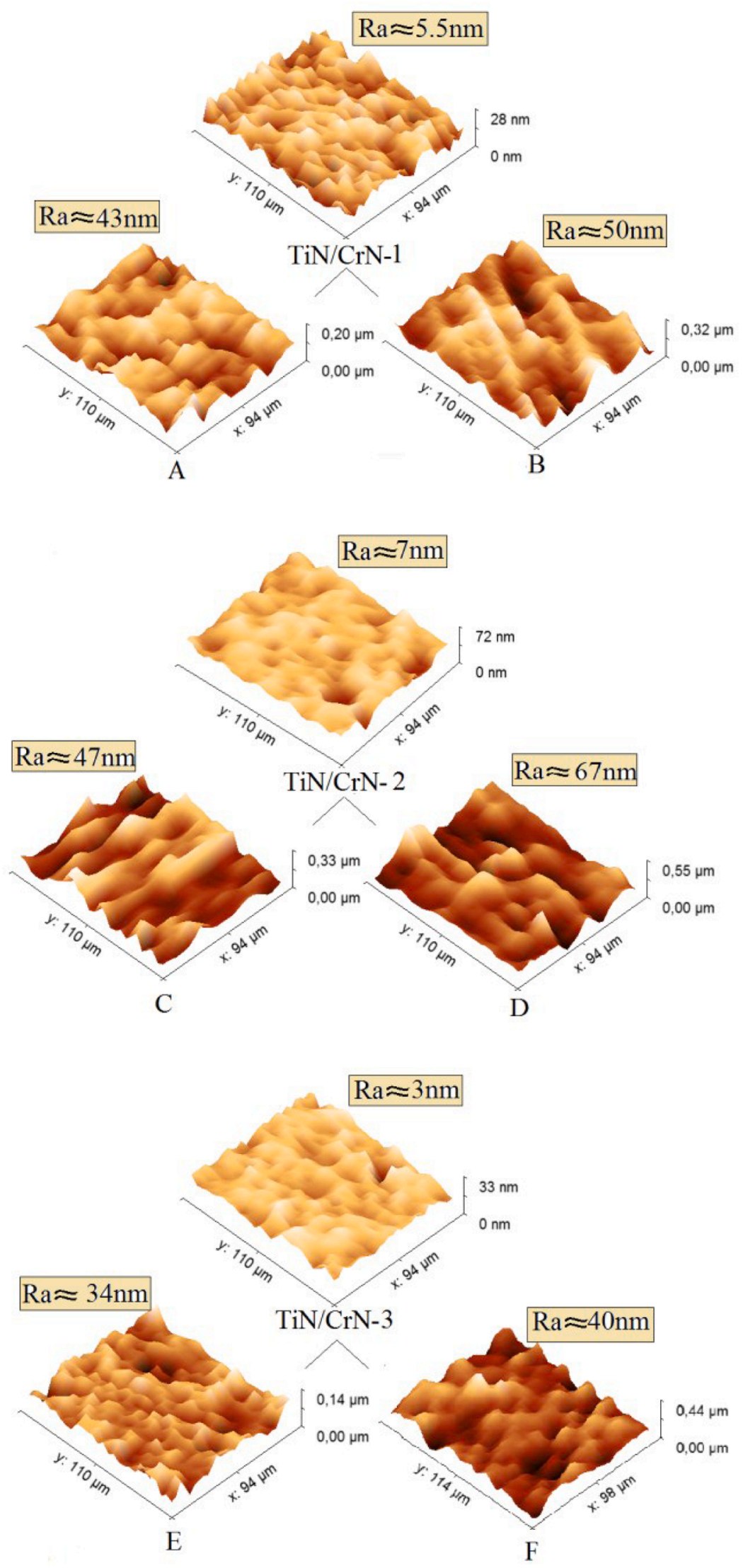

Fig. 2. Three-dimensional surface topography of: TiN/CrN-1, TiN/CrN-2, TiN/CrN-3 on Si substrates and TiN/CrN-A, B, C, D, E and F, on steel substrates. 

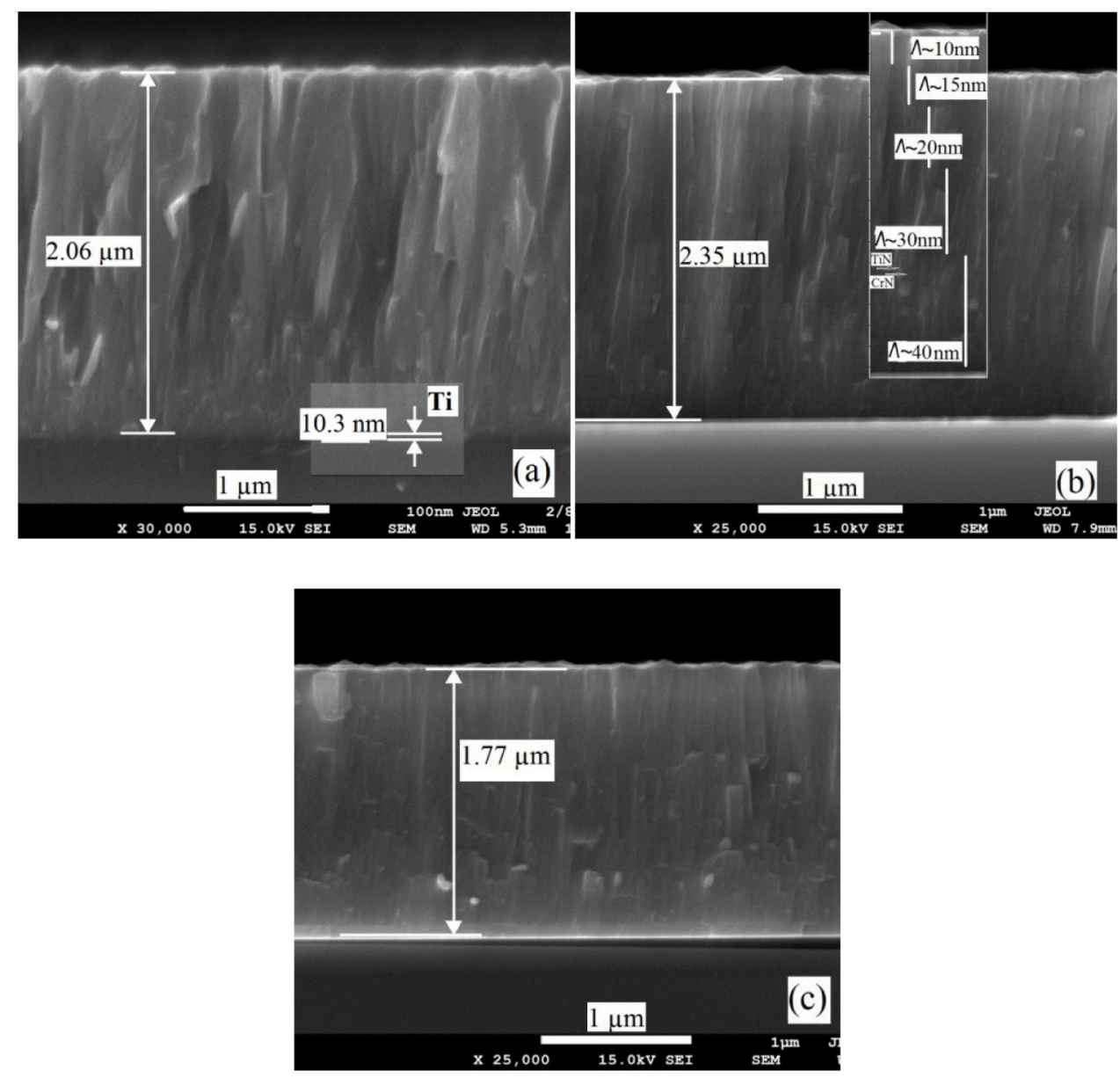

Fig. 3. Cross-section SEM images of (a) TiN/CrN-1, (b) TiN/CrN-2 and (c) TiN/CrN-3 multilayers deposited on Si substrates

Table 2

The EDS-WDS microanalyses results of the TiN/CrN Coatings (average values)

\begin{tabular}{|c|c|c|c|c|c|c|c|c|c|c|}
\hline \multirow[t]{2}{*}{ Coating TiN/CrN } & \multicolumn{2}{|l|}{$\mathrm{N}$} & \multicolumn{2}{|l|}{$\mathrm{Ti}$} & \multicolumn{2}{|l|}{$\mathrm{Cr}$} & \multicolumn{2}{|l|}{$\mathrm{O}$} & \multirow[t]{2}{*}{$\mathrm{N} / \mathrm{Me}$} & \multirow[t]{2}{*}{$\mathrm{Ti} / \mathrm{Me}$} \\
\hline & mass $\%$ & at $\%$ & mass $\%$ & at $\%$ & mass $\%$ & at $\%$ & mass $\%$ & at $\%$ & & \\
\hline 1 & 14.7 & 36.7 & 40.2 & 29.5 & 42 & 28 & 2.6 & 5.8 & 0.64 & 0.513 \\
\hline 2 & 15.3 & 38.33 & 40.8 & 29.8 & 42.3 & 28.5 & 1.6 & 3.4 & 0.66 & 0.511 \\
\hline
\end{tabular}

the TiN/CrN-A (Fig. 4(c)) and TiN/CrN-B (Fig. 4(d)) multilayer coatings, with peak positions at $36.91^{\circ}$ and $37.085^{\circ}$ respectively, were located between the $\operatorname{TiN}_{(111)}$ and $\mathrm{CrN}_{(111)}$ theoretical angle reflections $36.8^{\circ}$ and $37.53^{\circ}$ respectively. The (111) peaks become more apparent for coatings having larger bilayer periods. A decrease in the degree of the texture [100] is associated with a change in the stress-strain state of nitride layers. Similar findings have been reported in previous works [12, 22, 27, 31, 32]. As for the TiN/CrN-1 (A and B) structures, the primary characteristic peak of $\operatorname{TiN}_{(200)}$ located at $43.051^{\circ}$ and $43.125^{\circ}$, respectively, followed by the secondary characteristic peak of $\operatorname{CrN}_{(200)}$ located at $44.634^{\circ}$ and $44.73^{\circ}$, respectively, were distinguished on the XRD patterns. Although they were very close, they were identified thanks to their large periods $(\Lambda 20 \mathrm{~nm})$. Indeed, these phenomena revealed the gradual disappearance of epitaxial growth feature as observed by Harish et al. [18] and Zeng et al. [31].

The variation in interlayers' thickness influenced the microstructure change, since the coatings had a differences in crystallite size, even for those deposited on both substrates $\left(\mathrm{Ra}_{1}\right.$ and $\left.\mathrm{Ra}_{2}\right)$, at similar conditions. It is reported by Kumar et al. [22] that a slightly smaller grain size is observed for the film deposited on steel substrate than that deposited on silicon substrate. Moreover, the strong (200) preferred intensity was observed for the TiN/CrN-2 and TiN/CrN-3 coatings on rougher surface substrates corresponding to TiN/CrN-D and TiN/CrN-F (Fig. 4(f)). However, in the case of the TiN/CrN-1 coatings, the relatively (200) preferred orientation, was observed for the smoother substrate coated, corresponding to TiN/CrN-A coating (Fig. 4 (c)). This may be related to the tensile residual stress dominance in the thicker films (TiN/CrN-1 coatings) with a lower (0.64) stoichiometry ratio and higher (17 - 28 $\mathrm{nm}$ ) crystallite size, as opposed to the compressive residual stresses dominance for the thinner films (TiN/CrN-3 coatings) with a higher (0.68) stoichiometry ratio and smaller (6.9 $-11,5 \mathrm{~nm})$ crystallite size. Indeed, Kumar et al. [22] observed the compressive stress in the TiN thinner film with the (200) preferred orientation and the smaller crystallite size, whereas, the lattice parameter of the thicker film with the (111) preferred orientation and the higher crystallite size, was close to the reported value in JCPDS. Mendibide et al. [32] also found that the preferential orientation of the layer is related to the intensity of the residual stresses. Furthermore, some parameters such as stoichiometric deviation or the lattice defects growth during deposition may also affect the crystallite size. The crystallite sizes calculated from XRD using 

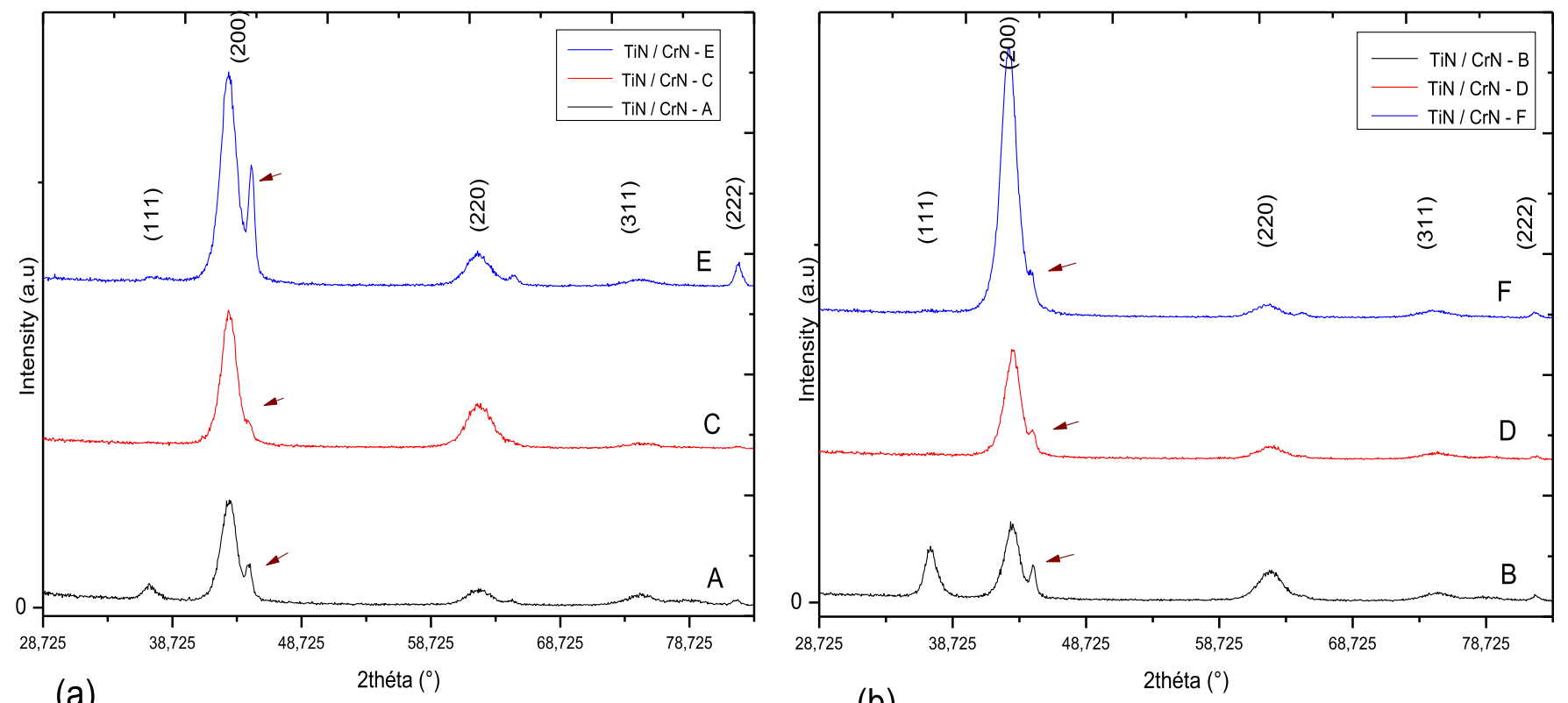

(b)

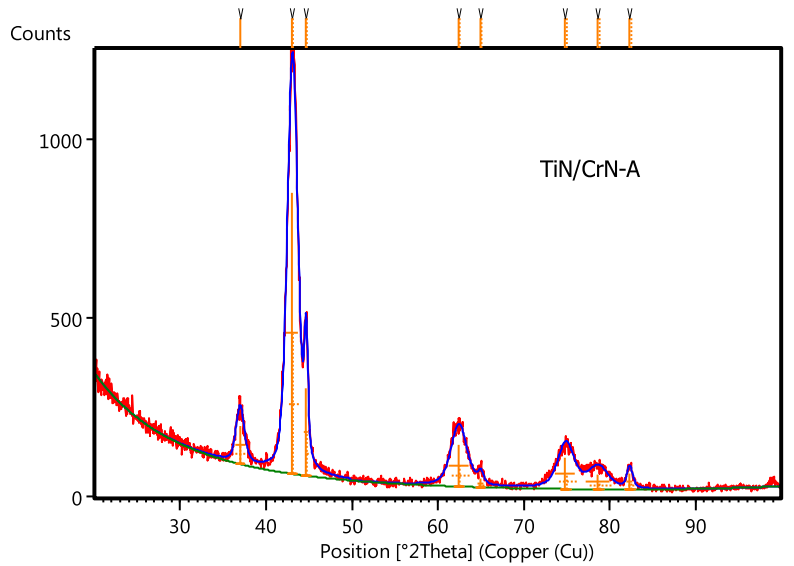

(c)

(d)
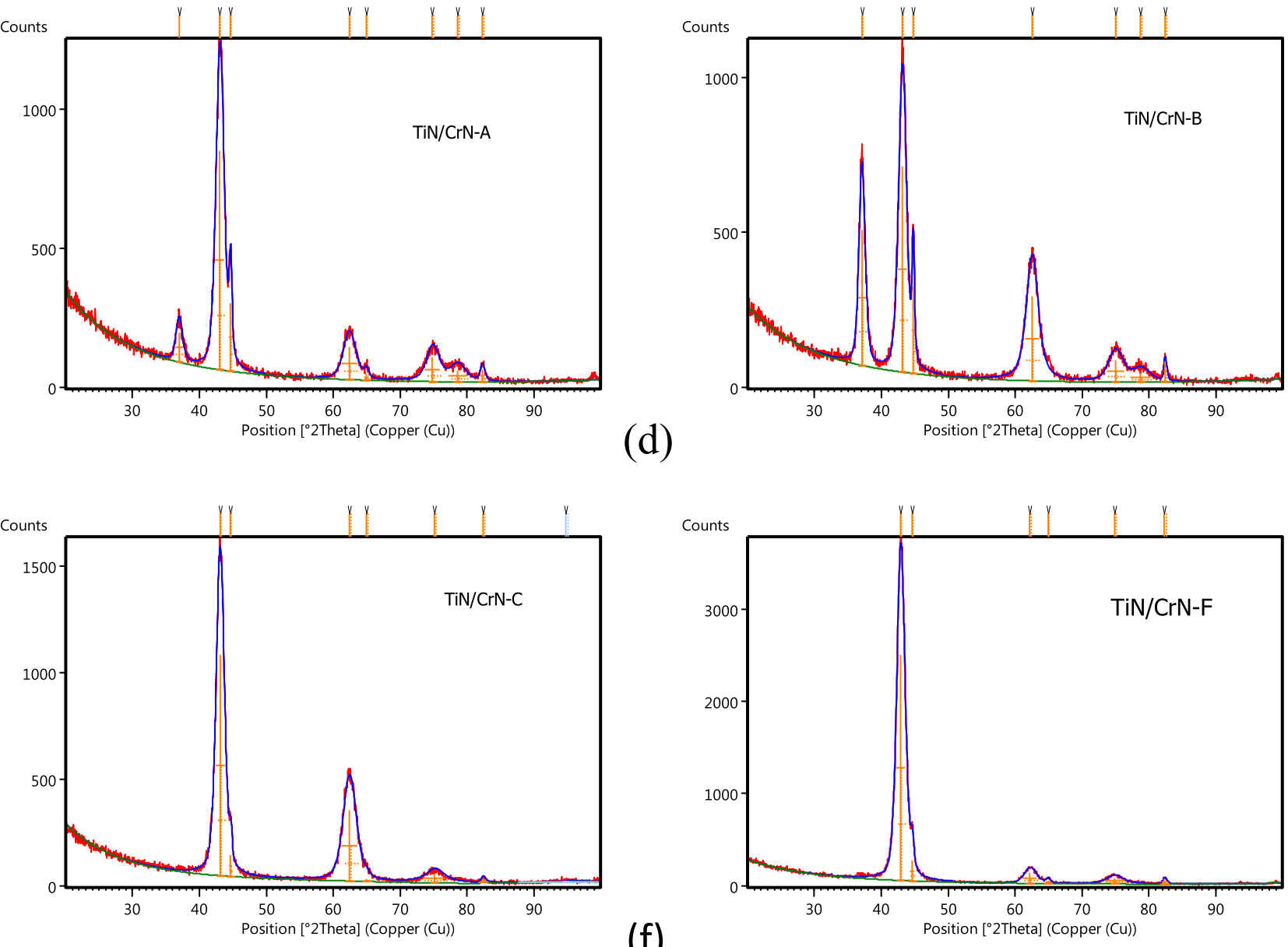

(e)

(f)

Fig. 4. X-Ray diffraction patterns of TiN/CrN-1, TiN/CrN-2 and TiN/CrN-3 coatings deposited on steel substrates: (a) Smoother substrate surface (Ra ${ }_{1}$ ), (b) rougher substrate surface $\left(\mathrm{Ra}_{2}\right)$, (c) TiN/CrN-A pattern, (d) TiN/CrN-B pattern, (e) TiN/CrN-C pattern and (f) TiN/CrN-F pattern. 
Williamson-Hall plot mode were higher in the coatings with rougher surface substrates than smooth substrates. They ranged from 7 to $28 \mathrm{~nm}$, endorsing the layer thickness influence on the crystallinity.

\subsection{Mechanical properties}

\subsubsection{Nanoindentation}

The hardness $(H)$ and the effective Young's modulus ( $\left.E^{*}\right)$ of the TiN/ $\mathrm{CrN}$ thin films were measured using standard nanoindentation, according to the Continuous Stiffness Measurement (CSM) technique and the Oliver \& Pharr model [21]. It can be seen from Fig. 5 that the indentation depths $H_{m}$ obtained for the softer film was 180nmand only $129 \mathrm{~nm}$ for the hardest film. The hardness values are function of the penetration depth. The plastic deformation energies $W p=W t o t-W e$ were defined by the integrated area formed by loading and unloading curves during indentation measurements, where Wtot is the total work during loading, $W e$ is the reversible (elastic recovery) work and $W p$ is the irreversible (plastic deformation) work. Additionally, the $H^{3} / E^{* 2}$ ratios were calculated to characterize resistance to plastic deformation. Thereby, the $H, E^{*}, H^{3} / E^{*}$ evolutions with the different multilayer configurations on both surface roughness substrates are illustrated in Fig. 6. Enhanced hardness was observed for the rougher $\left(\mathrm{Ra}_{2}\right)$ substrate. The $H$ and $E^{*}$ average values were found to decrease in the order(38.9 GPa, 32.7GPa and 26.46GPa) and (592.3 GPa, 407.8GPa and 341.2GPa), for the TiN/CrN-F, TiN/CrN-B and TiN/CrN-D coatings, respectively. According to the highest $H$ and $E^{*}$ values, the TiN/CrN-F showed the smallest plastic deformation energy $(W p=156 n J)$ with a high resistance to deformation $\left(H^{3} / E^{*^{2}}=0.19 \mathrm{GPa}\right)$. Similarly, the TiN/CrN-B exhibited the highest resistance to deformation $\left(H^{3} / E^{* 2}=\right.$ $0.21 \mathrm{GPa}$ ) with a low plastic deformation energy $(W p=285 \mathrm{~nJ})$. Indeed, Yang et al. [9] found that the (200) oriented superlattices exhibited higher hardness enhancement at $\Lambda=10 \mathrm{~nm}$ than the (111) oriented superlattices due to their more effective interface-dislocation interactions. Furthermore, it was found that hardness and effective Young's modulus increase with tensile residual stress in multilayer films as demonstrated by Bouaouina et al. [33] for the MoN/CrN films, deposited using RF magnetron sputtering. Effectively, the resistance to plastic deformation increase is coupled with the plastic deformation energy $W p$ decreases as the hardness increases $[13,18]$. It is well known that the hardness enhancement of multilayered coatings is due to the presence of interfaces that prevent deformation. The literature is rich in explanations of the mechanisms governing the dislocations motion across the interface of multilayer coatings, such as the Hall-Petch effect and the Kohler theory. The interfaces (grains or layers) act as barriers to dislocations propagation. Though Chu and Barnett [34] have suggested

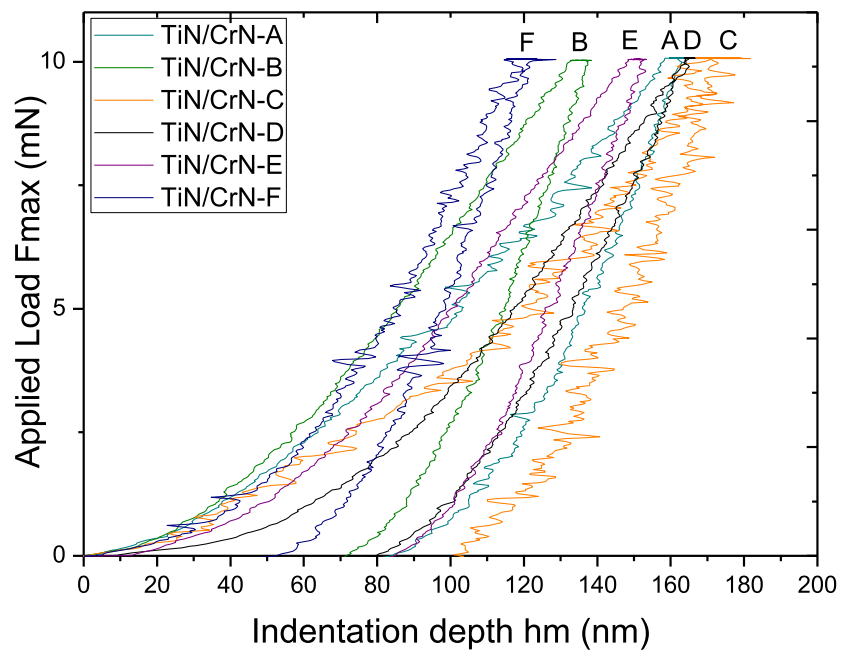

Fig. 5. Indentation load-displacement curves of the TiN/CrN multilayers.

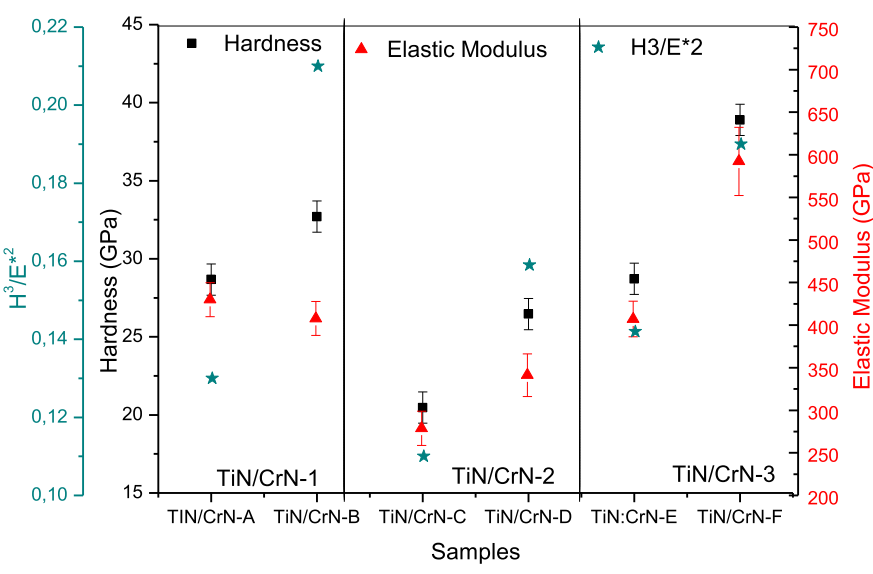

Fig. 6. Hardness, elastic modulus and $\mathrm{H}^{3} / \mathrm{E}^{*^{2}}$ ratio evolution of the TiN/CrN multilayers.

the difference in shear modulus as an explanation of the hardness enhancement in superlattices, Mendibide et al. [32] have likewise proposed the strain-stress effects at $\mathrm{TiN}$ and $\mathrm{CrN}$ interfaces. Changing film thickness is followed by the variation in dislocation mechanism [22].

The improved mechanical properties of the TiN/CrN-3, especially TiN/CrN-F, which were deposited on rough substrate, can be attributed to the low and constant $(\Lambda=12 \mathrm{~nm})$ thickness associated with the high (300) number of interfaces and the crystallite size reduction $(11.5 \mathrm{~nm})$, generated the high $(-163 \mathrm{MPa})$ residual stresses, consequence to the film densification. It is mentioned by Mayrhofer et al. [35] that hardness can increase with only minor changes in compressive stresses. Moreover, Kumar et al. [22] found that the film deposited on steel substrate exhibited lower lattice parameters, hence higher residual stresses, than that deposited in similar conditions on the smoother silicon. On the other hand Falsafein et al. [16] mentioned that the hardness of industrial coatings varies due to differences in microstructure, texture and stoichiometry. The grain (crystallite) size of the coating has, therefore, a direct relationship with hardness. The present results are in agreement with previous studies, where it was observed that enhancement in mechanical properties with the change in layer thicknesses, for both TiN/CrN and CrN/TiN superlattice coatings irrespective of the preferred orientation, as demonstrated for the (111) textured film [14, 15, 18], (200) textured film [4, 12, 27] or no preferred orientations $[9,13]$.

The lowest mechanical results $H=20.5 \mathrm{GPa}, E^{*}=279 \mathrm{GPa}$ and $H^{3}$ / $E^{*^{2}}=0.11 G P a$, according to the highest $W p$ value $(328 n J)$, were attributed to TiN/CrN-C. The decreased mechanical properties in TiN/ CrN-2 may be affected by the first thick bilayers' $(\Lambda \approx 40 \mathrm{~nm})$ growth (Hall-Petch effect associated to the high crystallite size $(18.6 \mathrm{~nm})$ ), the lower interface number and the lower residual stresses compared to the TiN/CrN-3. The change in mechanical properties of the coatings is directly related to the microstructure, texture, crystallite size, substrate effect and deformation behavior [22].

\subsubsection{Scratch test}

3.3.2.1. Scratch track analysis. The scratch test which is a useful technique for monitoring coating adhesion was used, to analyze the TiN/CrN multilayers behavior deposited on two different roughness substrates with varying inter-layer thicknesses. Under the same testing conditions, the adhesive failure mode of the coating was essentially identified as spallations and buckling failure mode. The scratch track morphologies of the TiN/CrN-B, TiN/CrN-D and TiN/CrN-F with the higher substrate roughness, exhibited a slight increase in cohesive/adhesive behavior compared to the other coatings (Fig. 7). This is essentially due to the surface asperities of the steel substrate acting as mechanically interlocking sites at the coating-substrate interfaces [4]. Besides, the 

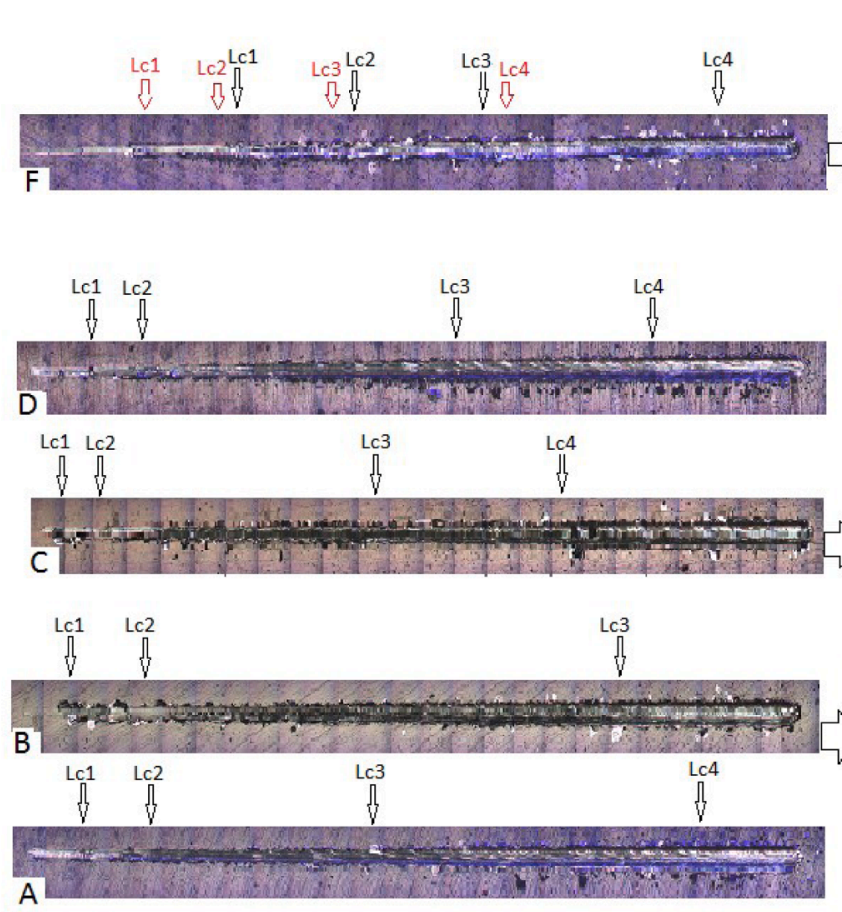

$\begin{array}{lllllllll}0 & 1 & 2 & 3 & 4 & 5 & 6 & 7 & (\mathrm{~mm})\end{array}$

a)

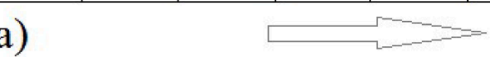

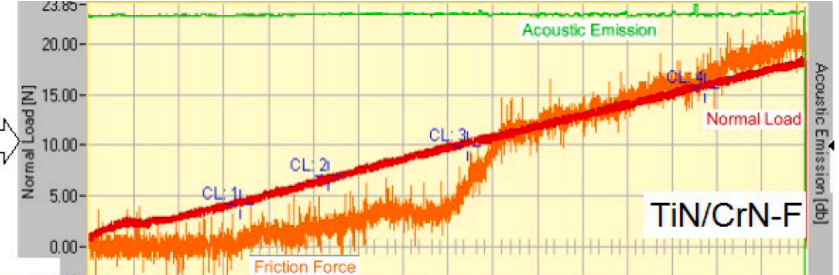

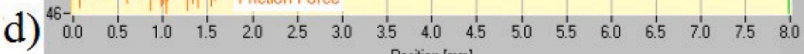

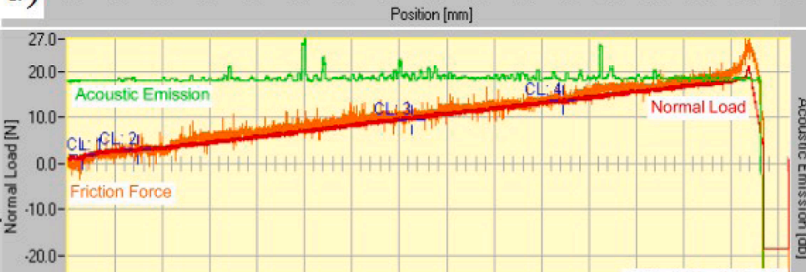

$\mathrm{TiN} / \mathrm{CrN}-\mathrm{C}$

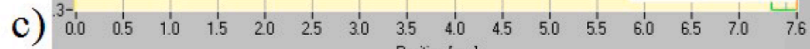
Postion $[$ mme $]$

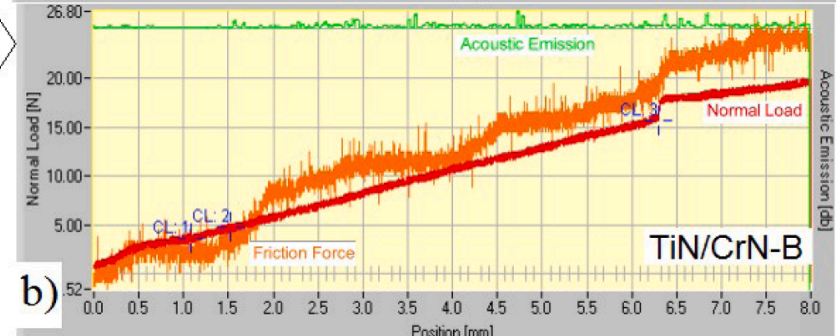

e)
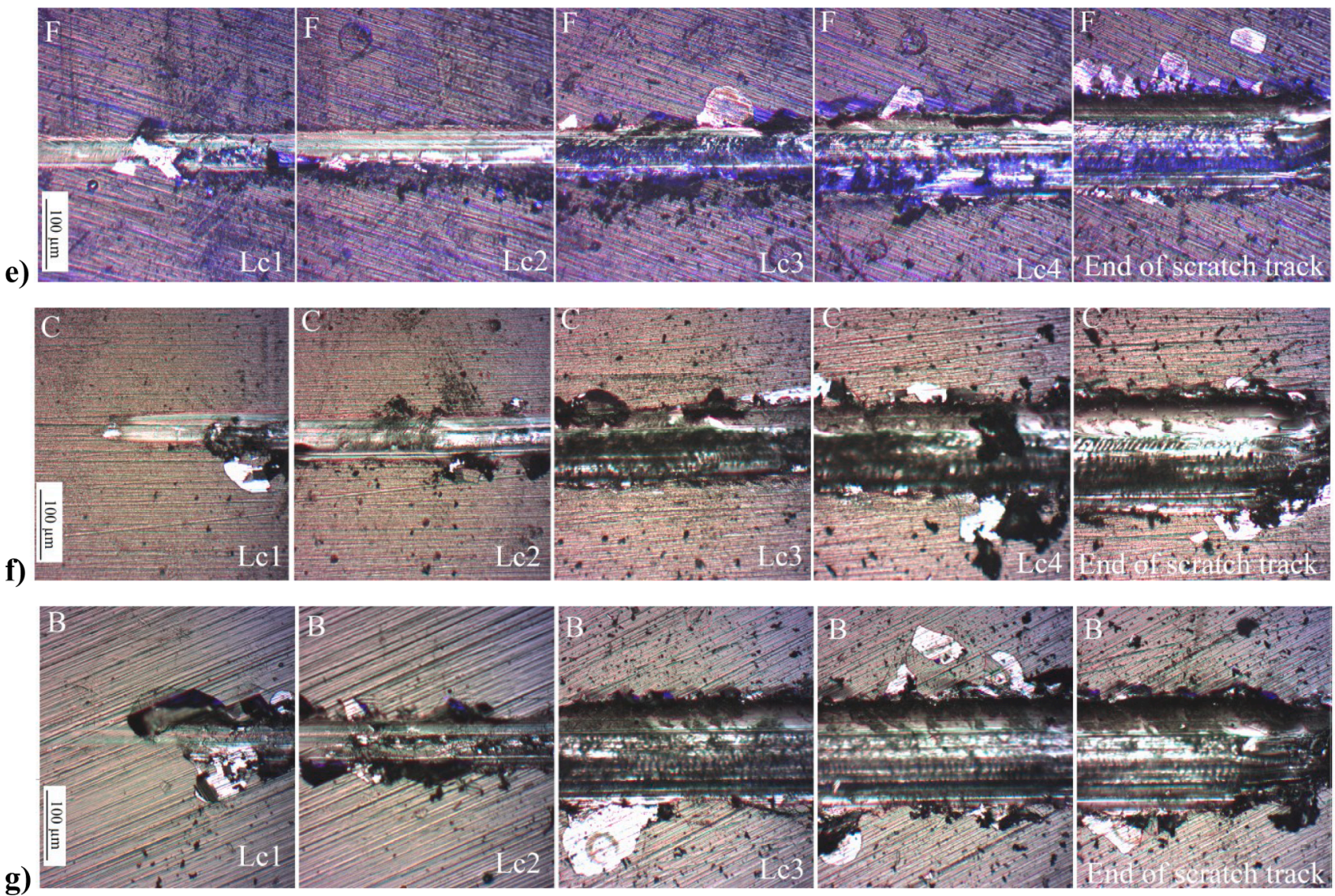

Fig. 7. Optical images of scratch tracks of the TiN/CrN multilayers (black arrow: average values and red arrow: minimum values) and TiN/CrN-B, C, and F corresponding cracking patterns and $\mathrm{AE}$ signal recorded during scratch test. 
TiN/CrN-F multilayer exhibited the lower failure intensity as the test proceeded. The coating had been smoothed (Fig. 7 (a) and (e)) in the first stage of the test, before ductile tensile cracks confined within the track appeared (Fig. 8(F)). This eventually leads to the beginning of cohesive failure of the coating. Thereafter, as the scratch test progressed, the coating displayed small spallations (Fig. 8(F)) producing the first delamination within the track in agreement with the small acoustic emissions generated as shown in Fig. 7(d). Such observation is explained by Bull et al. [36] who suggested that individual buckles of the coating are induced by the compressive stress ahead of the indenter combined with residual stresses still present in the coating. Consequently, the spalling failure resulted behind the diamond stylus contact when the trough thickness cracks occurred in response to the tensile stresses generated. As the test proceeded, extensive growth of the spalling regions was observed leading to exposure of the substrate (Fig. 7(e)). Regarding the deposit TiN/CrN-1, the TiN/CrN-B multilayer displayed (Figs. 7(a) and 8(B)) some similarities with the TiN/CrN-F multilayer coating, despite the few debris (Fig. $7(\mathrm{~g})$ ) developed in the first stage of the test, at lower loads. This may be due to the coating roughness which increased the coefficient of friction (COF) and hence the shear traction on the coating [6]. Likewise, the main acoustic emission level also increased (Fig. 7(b)). However, adhesion failure was observed at high load in the form of few substrate exposures (Fig. 7(g)). The behavior of the TiN/CrN-2 multilayer was somewhat different. The TiN/CrN-C multilayer exhibited the lowest adhesion resistance (Fig. 7(a) and (f)). A large number of spalls occurred at the start of the test (Fig. 8(C)) and continued along the track. As the amount of cracks and spalls increased with the applied load, the acoustic emission also increased (Fig. 7(c)). Additionally, the TiN/CrN-A and the TiN/CrN-D have displayed approximately similar cracking patterns as shown in Fig. 8(A) and 8(D), respectively. High amount of coating remained bonded to the substrate at the end of the scratch tracks for all samples (Fig. 7). The cracking behavior of the films was quite similar to that observed in previous work for the TiN coating deposited by magnetron sputtering [37] and by cathodic arc evaporation [38].

3.3.2.2. Adhesion measurement. A quantitative analysis by measuring the critical load values was achieved in order to estimate the coatings adhesion work $W_{a d}$. This was done using the Bull and Rickerby [39] equation: $\mathrm{Wad}=\frac{8^{2}}{2 \pi^{2}} \frac{h \times L_{c}^{2}}{E^{*} \times d^{4}}$, where $\mathrm{Wad}$ is the adhesion work which is the key to predicting the mechanical properties of an interface, $h$ the coating thickness, $L_{c}$ the adhesion/coating fracture critical load (coating separates from the substrate at $L_{c 3}$ ), $E^{*}$ the elastic modulus of the coating and $d$ the scratch width measured at the adhesive critical load $\left(L_{c 3}\right)$.

The critical loads $\left(L_{c 1}, L_{c 2}, L_{c 3}\right.$ and $\left.L_{c 4}\right)$ of the multilayer coatings were characterized respectively by: the semi-circular cracks inside the scratch track detected by the first $L_{c 1}$ (which can characterize the material toughness); the first cohesive chipping at the edges evaluated by $L_{c 2}$; the first delamination within the track was associated with $L_{c 3}$; and massive delamination detected for $L_{c 4}$. The experimental results are summarized in Fig. 9. It is noted that the coatings on rougher surface substrates exhibited higher cohesive/adhesive critical loads. As reported in Fig. 10 the estimated values of the adhesion work Wad has increased with the hardness in the TiN/CrN-1, and has decreased as the hardness increased in the TiN/CrN-2.

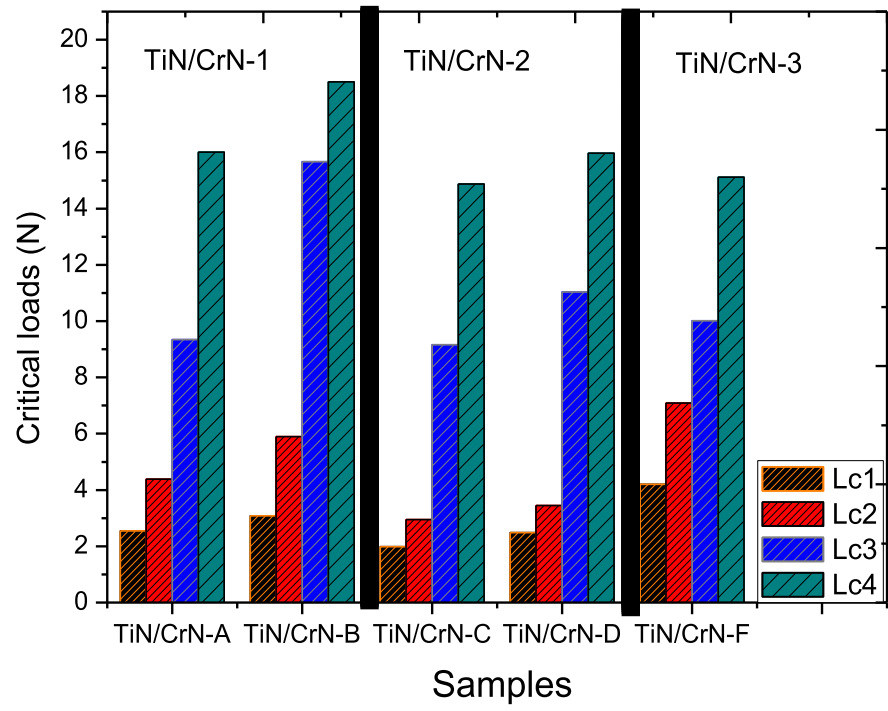

Fig. 9. Critical loads $L_{c}$ measured for the TiN/CrN multilayers (the TiN/CrN-E is not included)
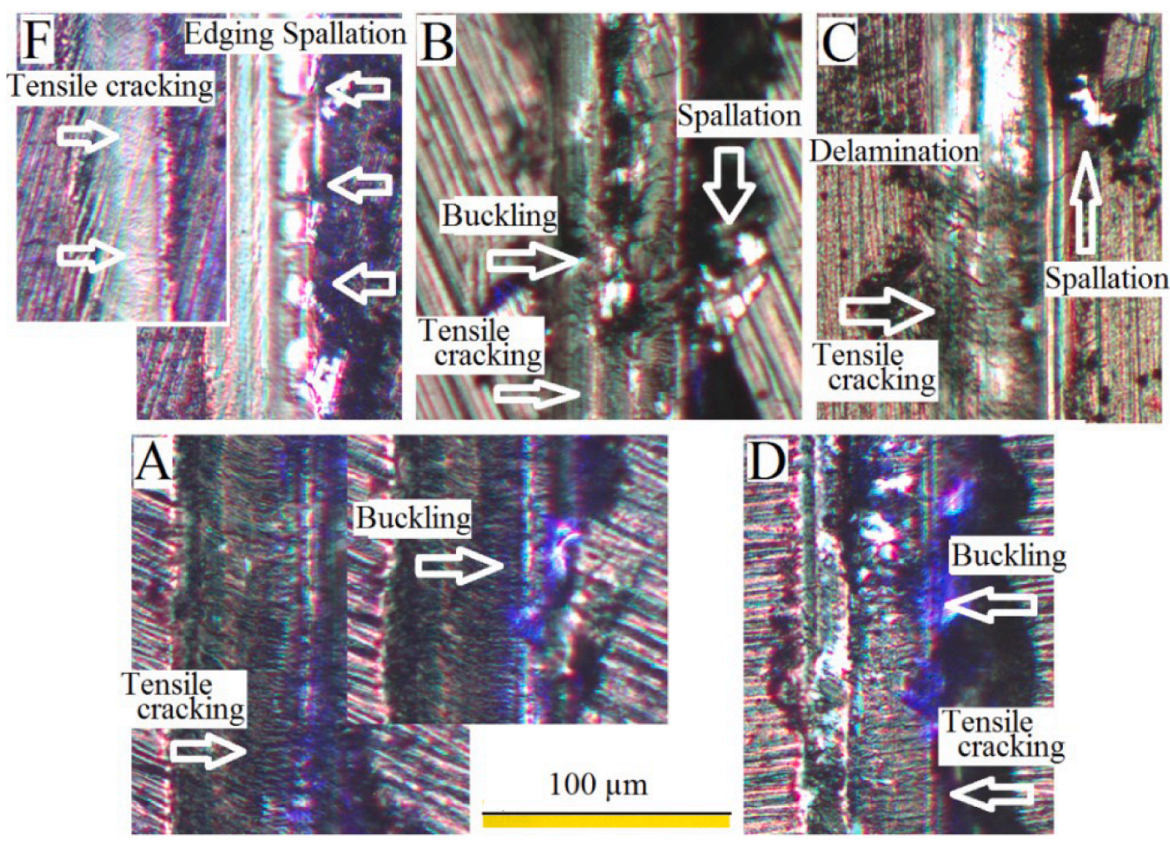

Fig. 8. Optical images of coating failures obtained in the TiN/CrN multilayers scratch tracks 


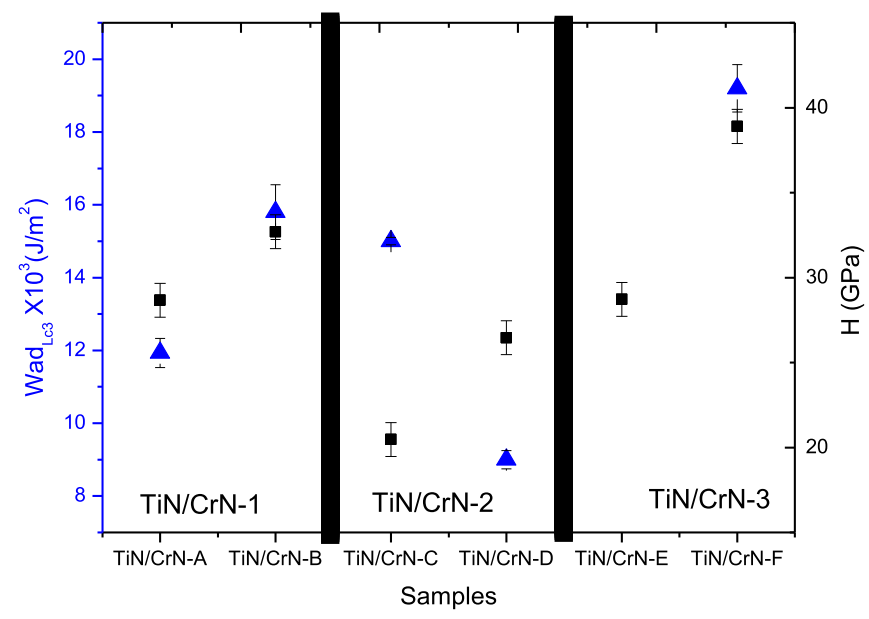

Fig. 10. Evolution of the adhesion work and hardness of the TiN/CrN multilayers

As expected, the TiN/CrN-F coating exhibited the highest $L_{c 1} \approx 4.3 \mathrm{~N}$ and $L_{c 2} \approx 6.98 \mathrm{~N}$ values, according to the better mechanical properties, which led to toughness enhancement. Cracks can be stopped at each interface (300 interfaces), due to effective interface dislocation interactions in the (200) oriented superlattices [9], and can cause a delamination of the top layer, which is in agreement with the literature $[7,15,31]$. Additionally, it is well known that smooth coating surface contribute to enhance coating adhesion [30, 39]. However, at high loading, the TiN/CrN-F exhibited lower critical load $\left(L_{c 3} \approx 12 N\right.$ and $L_{c 4}$ $\approx 15.6 N$ ). This may be due to the high compressive residual stresses concentrated at the vicinity of the interface-substrate. Bull [36] found that critical load for coating detachment is reduced as the residual stress in the coating increases. Although it improves wear resistance and hardness of the coating, it has an undesirable effect on adhesion performance [16]. In contrast, the TiN/CrN-B displayed the highest adhesive strength $\left(L_{c 3} \approx 15.1 \mathrm{~N}\right.$ and $L_{c 4}>20 \mathrm{~N}$ ), related to its better resistance to plastic deformation $(0.21 \mathrm{GPa})$ and appropriate residual stresses $(+$ 66.88MPa). Moreover, Lomello et al. [15] reported that the multilayer with (200) orientation dominant phase was harder but more brittle than the (111) phase. This was also confirmed in other works [31, 40]. It may be also due to the TiN/CrN-3 lower film thickness $(1.78 \pm 0.05 \mu m)$ as compared with TiN/CrN-1 and TiN/CrN-2, $(2.03 \pm 0.05 \mu m$ and $2.3 \pm$ $0.05 \mu \mathrm{m}$, respectively). The coating thickness effect has been widely reported [6, 16, 22, 37].

The TiN/CrN-A, B, C, and D, multilayers exhibited significantly lower $L_{c 1}<3 N$ and $L_{c 2}<5.5 N$, which led to lower cohesive action. However the adhesive action was somewhat similar to that of the TiN/ CrN-F displayed by $L_{c 3}$. As for the TiN/CrN-C multilayer, the lowest cohesive critical loads $\left(L_{c 1} \approx 1.73 N, L_{c 2} \approx 2.87 N\right)$ were observed. These lower values can be attributed to the significantly lower resistance to plastic deformation (0.11) as shown in Fig. 6.

Although Deqiang et al. [41] have demonstrated that the calculated value of Wad increase almost linearly with the residual stress which shrinks interfacial Ti-N and Cr-N bonds, and strengthens their electronic interactions. It is evident that, practical adhesion depends not only on the stresses in the coating but also, on interfacial number, thickness and mechanical properties of the coating and substrate.

\section{Conclusion and perspectives}

Three TiN/CrN multilayers, with varying modulated period $(\Lambda)$ and interlayer thicknesses, were deposited using magnetron sputtering process on XC48 steel substrates with two different surface roughnesses. The aim was to investigate the interaction of the intrinsic characteristics of the coatings and their effect on the mechanical behavior to improve their tribological properties.

The chemical analysis revealed the sub-stoichiometric state for all the coatings. The TiN/CrN multilayers growth was affected by thickness and substrate roughness variations. A preferred (200) orientation for all the coatings were observed. The emergence of the (111) plan was observed for those with higher interlayer thicknesses.

The improvements in hardness $(H>40 G P a)$, Young's modulus $\left(E^{*}>\right.$ $600 \mathrm{GPa})$ and resistance to plastic deformation $\left(\mathrm{H}^{3} / \mathrm{E}^{* 2}>0.20 \mathrm{GPa}\right)$ were attributed to the coating with the strong (200) preferred orientation, and lower period $(\cong 12 \mathrm{~nm})$ with the $1.7 / 1$ thickness ratio. The interface number increase contributed to toughness and cohesive strengths increase. The coatings on the rougher substrate surface exhibited enhanced hardness and greater adhesion strength than those deposited on smoother steel substrates. The adhesive failure mode of the coatings was essentially identified as spallations and buckling failure modes.

No significant mechanical behavior improvement was observed with the progressive variation in modulation sequence $(40-30-20-15-$ $10 \mathrm{~nm})$. However, an improvement in their surface hardness (43.3 $\mathrm{GPa}$ ), was noted at $6 \%$ depth of the coating surface.

These results will be correlated with frictional and wear resistance properties of the TiN/CrN multilayers coatings in a forthcoming study.

\section{Declaration of Competing Interest}

The authors have no conflicts of interest to declare.

\section{Acknowledgements}

The authors would like to thank the General Directorate of Scientific Research and Technological Development (DGRSDT, Algeria) for their support to the present work (PRFU N ${ }^{\circ}$ A11N01UN350120180004) and express their gratitude to the CDTA (Centre for the Development of Advanced Technologies) for the use of their scientific equipments. A major part of this work was carried out at the LaBoMaP, Arts et Metiers Institute of Technology, Rue Porte de Paris Cluny 71250, France, at the MSMP laboratory of Lille, France and at the UR-MPE, Université M'hamed Bougara, Boumerdes, Avenue Independence 35000, Algeria. The authors would especially like to thank Dr. Aurélien Besnard for his assistance in the production of coatings, Denis Lagadrillère for the SEM analysis and Alberto Mejias for the Scratch test measurements.

\section{References}

[1] M.M. Khruschov, Resistance of metals to wear by abrasion as related to hardness, J. Mech. Eng., Lond. 48 (1957) 655-659.

[2] W.D. Sproul, New routes in the preparation of mechanically hard films, Science 273 (1996) 889-892, https://doi.org/10.1126/science.273.5277.889.

[3] H. Aknouche, A. Zerizer, C. Nouveau, S. Kennouche, N. Sitouah, H. Boulahia, in: Couches minces dures type Cr-Al-N pour outils de coupe du bois, International Congress on Materials\& Structural Stability, Rabat, Morocco, 27-30 November 2013.

[4] D.D. Kumar, N. Kumar, S. Kalaiselvam, S. Dash, R. Jayavel, Wear resistant superhard multilayer transition metal-nitride coatings, Surfaces and Interfaces 7 (2017) 74-82.

[5] R. Ali, M. Sebastiani, E. Bemporad, Influence of Ti-TiN multilayer PVD-coatings design on residual stresses and adhesion, Materials and Design 75 (2015) 47-56, https://doi.org/10.1080/00207840410001733940.

[6] S.J. Bull, Can scratch testing be used as a model for the abrasive wear of hard coatings, Wear 233-235 (1999) 412-423, https://doi.org/10.1016/S0043-1648 (99)00209.

[7] J.S. Koehler, Attempt to design a strong solid, Phys. Rev. B 2 (1970) 547-551, https://doi.org/10.1103/PhysRevB.2.547.

[8] M. Nordin, M. Larsson, S. Hogmark, Mechanical and tribological properties of multilayered PVD TiN/CrN, TiN/MoN, TiN/NbN and TiN/TaN coatings on cemented carbide, Surf. Coat. Technol. 106 (1998) 234-241, https://doi.org/ 10.1016/S0257-8972(98)00489-7.

[9] Q. Yang, C. He, L.R. Zhao, J-P. Immarigeon, Preferred orientation and hardness enhancement of TiN/CrN superlattice coatings deposited by reactive magnetron sputtering, Scripta Materialia 46 (2002) 293-297, https://doi.org/10.1016/S13596462(02)00154-9.

[10] H.C. Barshilia, M. Suruya Prakash, A. Jain, K.S. Rajam, Structure, hardness and thermal stability of TiAlN and nano-layered TiAlN/CrN multilayer films, Vacuum 77 (2005) 169-179, https://doi.org/10.1007/s11431-010-3176-4. 
[11] O.V. Sobol, A.A. Meilekhov, Conditions of Attaining a Superhard State at a Critical Thickness of Nanolayers in Multiperiodic Vacuum-Arc Plasma Deposited Nitride Coatings, Technical Physics Letters 44 (1) (2018) 63-66, https://doi.org/10.1134/ s1063785018010224.

[12] Y.M. Zhou, U.R. Asaki, K. Higashi, W.H. Soe, R. Yamamoto, Sliding wear behavior of polycrystalline TiN/CrN multilayers against an alumina ball, Surf. Coat. Technol. 130 (2000) 9-14, https://doi.org/10.1016/S0257-8972(00)00673-3.

[13] Q. Yang, L.R. Zhao, Dry sliding wear of magnetron sputtered TiNyCrN superlattice coatings, Surf. Coat. Technol. 173 (2003) 58-66, https://doi.org/10.1016/S0257 8972(01)01003.

[14] Y.X. Ou, J. Lin, H.L. Che, J.J. Moore, W.D. Sproul, M.K. Lei, Mechanical and tribological properties of TiN/CrN superlattice coatings deposited by a combination of arc free oscillation magnetron sputtering, Thin Solid Films 594 (2015) 147-155, https://doi.org/10.1016/S0040-6090(15)01081.

[15] F. Lomello, M. Arab Pour Yazdi, F. Sanchette, F. Schuster, M. Tabarant, A. Billard, Temperature dependence of the residual stresses and mechanical properties in TiN/CrN nanolayered coating processed by cathodic arc deposition, Surf. Coat. Technol. 238 (2014) 216-222.

[16] M. Falsafein, F. Ashrafizadeh, A. Kheirandish, Influence of thickness on adhesion of nano-structured multilayer $\mathrm{CrN} / \mathrm{CrAlN}$ coatings to stainless steel substrate, Surfaces and Interfaces 13 (2018) 178-185. doi:10.1007/s11771-018-3755.

[17] G.G. Stoney, The tensions of metallic films deposited by electrolysis, Proc. R. Soc. Land. A82 (1909) 172-175, https://doi.org/10.1098/rspa.1909.0021.

[18] H.C. Barshilia, K.S. Rajam, Deposition of TiN/CrN hard superlattices by reactive DC. Magnetron sputtering, Bull. Mater. Sci. 26-2 (2003) 233-237, https://doi.org/ 10.1007/BF02707797.

[19] K. Rzepiejewska-Malyska, M. Parlinska-Wojtan, K. Wasmer, K. Hejduk, J. Michler, In-situ SEM indentation studies of the deformation mechanisms in TiN, CrN and TiN/CrN, Micron 40 (2009) 22-27, https://doi.org/10.1016/j. micron.2008.02.013.

[20] H. Buckel, J.H. Westbrook, H. Conrad, The science of hardness testing and its research application, 453, American Society for Metals, Metals Park, OH, 1953.

[21] W.C. Oliver, G.M. Pharr, An improved technique for determining hardness and elastic modulus using load and displacement sensing indentation experiments, J. Mater, Res. 7 (1992) 1564-1587, https://doi.org/10.1557/JMR.1992.1564.

[22] D. Dinesh Kumar, N. Kumar, S. Kalaiselvam, R. Thangappan, R. Jayavel, Film thickness effect and substrate dependent tribo-mechanical characteristics of titanium nitride films, Surf. Coat. Technol. 12 (2018) 78-85, https://doi.org/ 10.1016/j.surfin.2018.05.002.

[23] M. Nordin, M. Larsson, Deposition and characterization of multilayered PVD TiN/ CrN coatings on cemented carbide, Surf. Coat. Technol. 116-119 (1999) 108-115.

[24] L.E. Toth, Transition metal carbides and nitrides, Academic Press, London, 1971, https://doi.org/10.1002/ange.19720841920.

[25] H.A. Wriedt, J.T. Murray, The N-Ti (Nittrogen-Titanium) system, Bull. Alloy Phase Diagrams 8 (1987) 378-388. doi:10.1007/BF02869274.

[26] Y. Zhou, R. Azaki, W.H. Soe, R. Yamamoto, R. Chen, Hardness anomaly, plastic deformation work and fretting wear properties of polycrystalline TiN/CrN multilayers, Wear 236 (1999) 159-164.
[27] C.-Y. Su, C.T. Pan, T.P. Liou, P.T. Chen, C.K. Lin, Investigation of the microstructure and characterizations of TiN/CrN nano-multilayer deposited by unbalanced magnetron sputter process, Surf. Coat. Technol. 203 (2008) 657-660, https://doi.org/10.1016/j.surfcoat.2008.05.057.

[28] O.V. Sobol, A.A. Postelnyk, A.A. Meylekhov, A.A. Andreev, V.A. Stolbovoy, V. F. Gorban, Structural Engineering of the Multilayer Vacuum Arc Nitride Coatings Based on Ti, Cr, Mo and Zr, Journal of Nano- and Electronic Physics 9 (3) (2017), https://doi.org/10.21272/jnep.9(3).03003, 03003-1-03003-6.

[29] J. Pelleg, L.Z. Zevin, S. Lungo, Reactive sputter-deposited thin film on glass substrates, Thin Solid Film 197 (1991) 117-128, https://doi.org/10.1016/ 0040.6090(91).90225.

[30] Y.X. Ou, J. Lin, H.L. Che, J.J. Moore, W.D. Sproul, M.K. Lei, Structure, adhesion and corrosion behavior of $\mathrm{CrN}$ /TiNsuperlattice coatings deposited by the combined deep oscillation magnetron sputtering and pulsed dc magnetron sputtering, Surface Surf. Coat. Technol. 293 (2016) 21-27, https://doi.org/10.1016/j. surfcoat.2015.10.009.

[31] X.T. Zeng, S. Zhang, C.Q. Sun, Y.C Liu, Nanometric-layered CrN/TiN thin films: mechanical strength and thermal stability, Thin Solid Films 424 (2003), https:// doi.org/10.1016/s0040-6090(02)00921, 99-102.C

[32] P.Steyer Mendibide, J. Fontaine, P. Goudeau, Improvement of the tribological behavior of PVD nanostratifiedTiN/CrN coatings -An explanation, Surf. Coat. Technol. 201 (2006) 4119-4124, https://doi.org/10.1016/j.surfcoat.2006.08.013.

[33] B. Bouaouina, A. Besnard, S.E.H. Abaidia, F. Haid, Residual stress, mechanical and microstructure properties of multilayer Mo2N/CrN coating produced by R.F Magnetron discharge, App. Surf. Sci. 395 (2017) 117-121, https://doi.org/ 10.1016/j.apsusc.2016.04.024

[34] X. Chu, S.A. Barnett, Model of superlattice Yield stress and hardness enhancements, J. Appl. Phys. 77 (9) (1995) 4403-4411, https://doi.org/10.1063/1.359467.

[35] P.H. Mayrhofer, M. Geir, C. Locker, L. Chen, Influence of deposition conditions on texture development and mechanical properties of TiN coatings, Int. J. of Mater. Res. 100 (8) (2009) 1052-1058, https://doi.org/10.3139/146.110159.

[36] S.J. Bull, Failure modes in scratch adhesion testing, Surf. Coat. Technol. 50 (1991) 25-32, https://doi.org/10.1016/0257-8972(91)90188.

[37] K. Khlifi, H. Dhiflaoui, L. Zoghlami, A. BenChekhLarbi, Study of mechanical behavior, deformation, and fracture of nanomultilayer coatings during microindentation and scratch test, J. Coat. Technol. Res. 12 (2015) 513-524, https://doi.org/10.1007/s1199801596627.

[38] M. Lepicka, M. Gradzka-Dahlke, D. Pieniak, K. Pasierbiewicz, A. Niewczas, Effect of mechanical properties of substrate and coating on wear performance of TiN- or DLC-coated 316LVM stainless steel, Wear 382-383 (2017) 62-70.

[39] S.J. Bull, D.S. Rickerby, The inter-relationship between coating microstructure and the tribological performance of PVD coatings, in: Proceedings of the 16th LeedsLyon Symposium on Tribology held at The Institut National des Sciences Appliqués 17, 1990, pp. 337-349.

[40] D. Yin, X. Peng, Y. Quin, Z. Womg, Impact of residual stress on the adhesion and tensile fracture of TiN/CrN multilayered coatings from first principles, Phys. E. 44 (2012) 1838-1845, https://doi.org/10.1016/j.physe.2012.05.008.

[41] Y. Deqiang, P. Xiang, Q. Yi, W. Zhongchang, Impact of residual stress on the adhesion coating from first principles, Phys. E 44 (2012) 1838-1845. 